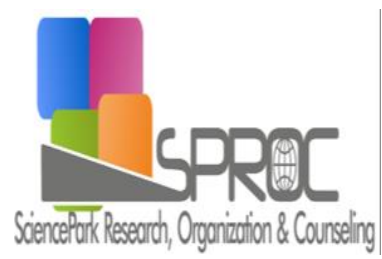

\title{
Credit risk measurement
}

Lucia Michalkova a *,

Katarina Frajtova Michalikova ${ }^{b}$

Suggested Citation:

Humanities and Social Sciences.

New Trends and Issues Proceedings on

Abstract

Lucia, Michalkova,

E-mail address 
1. Introduction

2. Credit risk models 


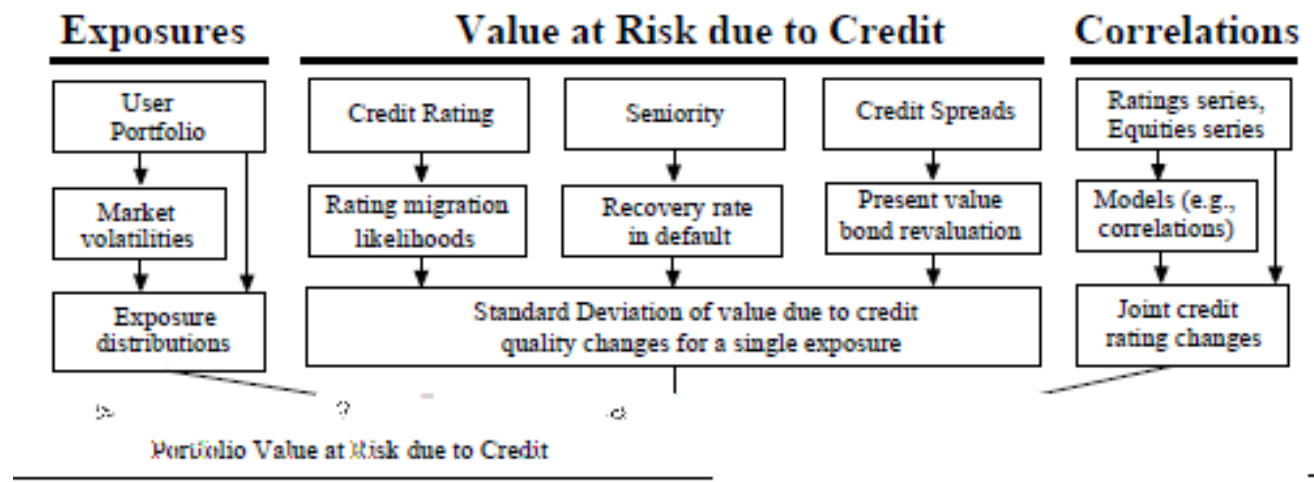

xposures Value at Risk due to Credit Correlations E

Figure 1 CreditMetrics framework

at risk due to Credit

Exposures, Correlations

Portfolio value

Value at Risk Due to Credit

1.

2.

3.

4.

Table 2. Transition Probabilities of Single A-bond Over Next Year, According to S \& P's for Five Years Maturity 
Table 3 Recovery Rates by Seniority Class

Seniority class Mean (\%) Standard deviation (\%)

Table 4 Forward rates and present value of bond by end of year

forward rates

Category
Year 1

Year 2

Year 3

Year 4
Present value of bond at the end of year (\$) 
Table 5. 4Standard Deviation Calculation for Bond Initially Rated Single A

\begin{tabular}{cccccc}
$\begin{array}{c}\text { Year-end } \\
\text { rating }\end{array}$ & $\begin{array}{c}\text { Probability } \\
\text { of state }\end{array}$ & $\begin{array}{c}\text { New bond } \\
\text { value }\end{array}$ & $\begin{array}{c}\text { Probability } \\
\text { weighted } \\
\text { value }\end{array}$ & $\begin{array}{c}\text { Difference } \\
\text { of value } \\
\text { from mean }\end{array}$ & $\begin{array}{c}\text { Probability weighted } \\
\text { difference squared }\end{array}$ \\
\hline
\end{tabular}

$$
\sigma=\sqrt{(96,84-2 * 26,86)-187,07^{2} * 0,00006}=2,84
$$

\section{Conclusion}




\section{Acknowledgements}

\section{References}

Social Sciences Research (SSR 2014): Proceedings of 2014 2nd international conference: December 10-11, 2014, Hong Kong

Economics and finance

Procedia

Credit risk: Pricing, measurement, and management

spectrum 4

Ekonomicko-manazerske

2nd International Conference on Economics and Social Science (ICESS 2014): July 29-30, 2014, Shenzhen, China,

Conference on Applied Social Science: March 20-21, 2014, Singapore,

4th International

Science,

3rd International Conference on Economics and Social

Social Sciences Research (SSR 2014): Proceedings of 2014 2nd international conference: December 10-11, 2014, Hong Kong

Financial Institutions

10th International Scientific Conference Financial management of Firms and

International Conference on Transport Means, Transport Means - Proceedings of the International Conference

risk and other paradigms

Credit risk measurement: New approaches to value at

Rizika a modely vo financiach a $v$ bankovnictve 